\title{
On the Cultural Selection of Hua Chun: A Chinese Japanese Female Writer
}

\author{
Jirong Zhang ${ }^{1}$ \\ ${ }^{1}$ Department of Chinese Language and Literature, Jinan University, Guangzhou, China \\ Correspondence: Jirong Zhang. Tel: 86-158-8995-2426. E-mail: aisiyan99r@163.com
}

Received: May 15, 2018

Accepted: June 16, $2018 \quad$ Online Published: June 22, 2018

doi: $10.5539 /$ ass.v14n $7 \mathrm{p} 86$

URL: https://doi.org/10.5539/ass.v14n7p86

\begin{abstract}
Hua Chun, a Chinese Japanese female writer, embodies cross-border and cross-cultural characteristics in her creation. She pays attention to the ecological environment, chooses the theme of environmental protection, and chooses the "Earth Man" perspective to narrate. She shuttles between Japanese and Chinese cultures, transcends the dilemma of personal and national sentiments and faces human nature directly. On the one hand, she actively integrates Japanese culture. On the other hand, she is still attached to the traditional Chinese culture. She establishes a third cultural space after experiencing a cross-border cultural experience.
\end{abstract}

Keywords: cross-border, the third space, Hua Chun, cultural selection

\section{Introduction}

Hua Chun, a Chinese Japanese female writer, went to study in Japan in 1986 and entered the literary world in 1998 with her debut novel The Desert Storm. The novel was shortlisted for the first National Outstanding Environmental Literature Award in China. Furthermore, the State Environmental Protection Administration of China and the Chinese Writers Association, the Research Institute and the China Society for Environmental Literature once jointly held a special seminar for the novel, which caused a great response. After that, in 2001, she published a short story "I Love ECO"; in 2005, she published a novelette "Miss Jasmine's Red Handkerchief" in Shanghai Novel, and won Taiwan Federation of Overseas Chinese Literature Works Excellent Works Award; in 2009, she published essay Collection The Temptation of Silk: the Symbol of Civilization in Japan. She published a large number of travel prose in Chinese newspapers and periodicals. She wrote a column on Japanese culture for Taiwan's humanities magazines.

As a Chinese writer who lives in Japan as a Japanese citizen, she shuttles between Japanese and Chinese cultures, transcends the dilemma of personal and national sentiments and faces human nature directly. On the one hand, she actively integrates Japanese culture. On the other hand, she is still attached to the traditional Chinese culture. She establishes a third cultural space after experiencing a cross-border cultural experience.

At present, there are three researches on the works of Hua Chun, which mainly focus on the affirmation of the ecological environmental awareness embodied in her works. Lu Shiqing (Lu, 2010), a professor at Fudan University in China, uses Hua Chun's prose as an analysis object, affirming the subject and the theme of environmental protection, and thinks that she touched the Japanese spiritual space through observing the daily life of Japanese people and showed the history of Sino-Japanese cultural exchanges through observing Japanese customs. Zhang Ying (Zhang, 2013), a scholar, analyzes the theme of environmental protection from the perspective of feminism in Hua Chun's works and sorts out the causes and social background of environmental protection theme. Zhang Zhonge (Zhang, 2006), a literary editor, affirms the value of Hua Chun's creation, thinks that she is free from the autobiographical writing limitations of overseas Chinese students, reveals the relationship between man and nature, discusses human values, responsibility, and ethics.

Compared with other overseas Chinese writers, Hua Chun's works are unique in the topic of theme selection and narrative perspective. To sum up the theme of overseas Chinese literature creation, there are mainly the following two: One is to observe the customs of overseas countries in the identity and perspective of others, to write the hardships and the feeling of overseas life. The other is to write the memories of Chinese or Chinese stories, with drifting emotions and nostalgia for hometown. Due to the special dual identity of overseas Chinese, in their works, there are often cultural collisions, identity seeking, ethnic and racial emotional conflicts and 
integration. However, Hua Chun's creation is different from these works. She writes as the "Earthman" and does not write personal sadness and hardship. She focuses on the ecology of the earth and environmental protection, discusses the relationship between man and nature, and exposes the dual destruction of the expansion of desire to the natural environment and human nature.

\section{Method}

This article mainly uses the theory of narratology to analyze the cultural significance of Hua Chun's creative texts from the aspects of writing subject, narrative perspectives, characters, and narrative structure, and tries to find out the uniqueness of Hua Chun's works through the close reading of the text. The narratology theory used in this paper mainly refers to Genette's Narrative Discourse, New Narrative Discourse and Forster's Aspects of the Novel.

Hua Chun's novels are narrating from the perspective of omnipotence, which has both advantages and disadvantages. According to Genette's (Genette, 1990, p.69) classification of narrative perspectives, "the narrative perspectives are divided into three kinds: omnipotent narrative, viewpoint narrative, and out-point narrative. The omnipotent narrative is that the narrator is larger than the figure and knows everything." Hua Chun's novels all use omnipotent narratives. The narrator knows the antecedents of the story and controls the rhythm of the narrative. The adoption of this narrative perspective makes the plot of the novel ups and downs, and the characters have distinct personalities. According to Foster's (Foster, 1973, p. 128) point of view, "the omnipotent perspective allows the novelist to look at the person from the outside as a spectator." From this point of view, the omnipotent perspective also brings some disadvantages to the novel narrative. In Hua Chun's novel, the narrator will use the words of characters in the novel to express the author's viewpoints and ideas, thus making the characters somewhat conceptual and flat.

\section{Discussion}

\subsection{Facing the Dilemma of Humanity: Selecting Environmental Themes and the Perspective of "Earthman"}

As an overseas immigration writer, the uniqueness of Hua Chung's creation lies in the selection of themes and the perspective of the "Earthman": choosing environmental protection rather than foreign novels and homesickness as writing subjects, and choosing the perspective of the "Earthman" rather than an overseas immigrant to show the world of environmental protection.

This unique writing is strongly reflected in her first novel The Desert Storm and the prose Collection The Temptation of Silk: the Symbol of Civilization in Japan.

The novel The Desert Storm is written on the subject of environmental protection. Hua Chun wrote a story that took place in Japan, Africa, and China, and portrayed a series of vivid characters, showed the grand theme of that how humans should live in harmony with the earth, stick to the truth, goodness, and beauty of humanity, and called for the responsibility and mission of human beings who should protect the earth: the human survival community. The novel spans Japan, the United States, Africa, China, and Russia in space. The characters in the novel were the Japanese, the Chinese, the Africans, the Russians, the Americans, the British, and the Taiwanese. Because of a "2010 plan" of environmental protection projects, they came together to prepare for a feat to improve the environment in the Sahara. The story finally reveals the greed of human nature, the expansion of desire, and the evil consequences that it brings. Other than, it also shows the selflessness and brilliance of a group of "Earthmen" dedicated to the protection of the environment. The theme of the novel is grand, the structure is vertical and horizontal, and the characters portray vividly and magnificently.

The Temptation of Silk: a Symbol of Civilization in Japan is a collection of essays about Japanese culture. The collection is organized in the seasons of spring, summer, autumn and winter. It describes Japan's cultural architecture, and the natural scenery, customs throughout the year. It reflects the author's thinking about nature and life, and calls humans to cherish the natural environment and to be harmonious with the nature; it also reflects the author's aesthetic pursuit of natural harmony. For example, in the essay "Why the dances of the caterpillar Butterfly?" the author described that she went to the outskirts and saw very beautiful rape flowers, which reminded her of the white butterfly in memory and went to find it, but long search failed. After asking, it was known that the flower farmer used pesticides to make the flower more beautiful, so the caterpillars were killed before they became butterflies. For this reason, the author sighs with emotion that people pay too much for the pursuit of economic interests. Take rape flowers for example, the heavy use of pesticides did make the rape flowers more beautiful, so it attracted more tourists and brought economic benefits, but Children can't see the reproduction of the worms anymore, and they can not imagine the artistic conception of the lingering and romantic of the butterfly love flowers anymore. "For the sake of economic interests, is it worthwhile to sacrifice 
the life of the next generation?", Hua Chun wants to remind readers to think about environmental damage by asking questions. The same way of writing is also reflected in other essays, such as "A revolution in the human food chain - from the Shumei natural agricultural cultivation method", "Mysterious Shirakawago", "Iris flower: always looks well no matter how it appears". In these essays, the author praises beautiful natural scenery and expresses love for nature; In the essay of "Alien dog", the author also directly expressed the view that in the era of industrial civilization, when people pursue economic interests, they not only caused pollution of the natural environment, but also led to the relationship remind between people.

\subsection{Facing Human Nature and Human Heart: Rational Value Selection Beyond National Cultural Prejudice}

The national feelings between China and Japan are very complicated due to historical reasons. On the one hand, China and Japan are neighbors with a strip of water, and are homogenous in both race and culture. Compared with other countries and races, China and Japan have a natural sense of intimacy. On the other hand, the trauma and pain caused to the Chinese people by the Japanese invasion of China became a shadow that the people could not forget and lingered. Therefore, Chinese writers tend to write Japan with stereotypes. Domestic writers cannot to directly contact and understand Japan in depth, so writing on Japan is often imaginative and stereotyped, some works vilify and weaken Japan in order to cater to the anger of the domestic public, such as the creation of a large number of anti-Japanese dramas. Most of the Chinese writers in Japan, who described Japanese and Chinese in their works, were also not objective, when writing about Japan, it was easy to vilify Japan with national personal traumatic emotions, this situation was common in early overseas student literature, for example, in Jiang Pu's novel Tokyo Has a Green Sun, it is basically difficult to see a beautiful Japanese image, under the influence of ethnic prejudices, Tokyo's sun is "green" instead of "red". When describing the Chinese in Japan, it will also demonize the Chinese people. In such works, most women fall for the money and become a bargirl or the plaything of a man; men abandon their wives for the sake of the future. In these works, both the Japanese and the Chinese are somewhat exaggerated. Different from these works, in the writing, Hua Chun can break through the embarrassment of national emotions, abandon the prejudices, stand at the height of a "Earth Man", face the human nature and the human heart, and conduct a rational understanding and criticism of human nature.

Hua Chun studied in Japan at her own expense in the 1980s. During her first year in Japan, she needed to face the hard working life and academic pressure to experience the pains of discrimination. However, Hua Chun could break through the embarrassment of her "emotions" and avoid exposing her personal emotions in her works. She objectively and calmly observed the beauty and ugliness of the human heart, and meticulously portrayed the various moods of the characters in the predicament and expressed the warmth and indifference between people. "Miss Jasmine's Red Handkerchief" is a story written about a Chinese man who failed to graduate on schedule and his visa expired. However, in order to earn enough money to enable his son to study in the United States, he chose to work in Japan illegally. Although it is the same narrative theme of writing about the hardships of Chinese people living abroad. Hua Chun's narrative is not the same as the other Chinese writers in Japan. She does not write about Da Wu's embarrassing and tragic experiences, and does not distinguish Chinese and Japanese from their nationality. The characters in her writing are only the distinction between beauty and ugliness, good and evil. The author describes $\mathrm{Da} \mathrm{Wu}$, a Chinese tough father who persists in his hard work in order to enable his son to study in the United States. He is not handsome and powerful, but he is sincere, kind, honest and empathetic. When Miss Jasmine was in the valley, he silently paid attention to her and took care of her. The Japanese female Miss Jasmine and Chiyoko are smart, elegant and kind. Although Miss Jasmine was in the Ginza entertainment place, she kept pure quality; she was smart, capable, talented, and very enthusiastic. She not only gave $\mathrm{Da} \mathrm{Wu}$ material assistance when he was most troubled, but also helped him find a job and re-establish confidence in life. Before she died, she left all her money to $\mathrm{Da} \mathrm{Wu}$ to help him solve his son's tuition. Chiyoko is gentle and versatile. She was good at business management and was willing to help others. In Hua Chun's works, whether they are Chinese or Japanese, they trust and help each other. The work beyond the national boundaries, flashing the glory of humanity and be full of warmth.

In Japan, although there are right-wing elements, there are also many anti-war people and many enthusiastic people. They sincerely want to repent and remedy the harm caused to the Chinese people during the war. In "Miss Jasmine Red Handkerchief", the author expressed that the Japanese people's support for the Japanese government's assistance to China through the ODA program for environmental protection, and their attitude regarding the Japanese invasion of China through the words of Jasmine. In a long talk, Miss Jasmine honestly said, "The war that Japan invaded China brought a lot of disasters to the Chinese people and hindered the progress of China's social development. Recently, the government has just released the ODA Outline, which is said to provide China with a series of economic assistance In order to compensate for the war. I am very happy that part of the national tax paid by Japanese nationals will be allocated to ODA funds each year. Although there 
are always people in Japan that discriminate against and exclude China, they cannot represent most of the people after all." (Hua, 2008) Miss Jasmine's words are also Hua Chun's perception and judgment of the Japanese people. The experience of working in Japan enabled her to penetrate into the lives of the Japanese people. She was able to break through the national and personal emotions, objectively examine the humanity and ugliness of the Chinese and Japanese people, and did not use narrow human emotions, but adopted universal humanity as the criterion, All of these embody the transcendent spirit of Hua Chun as a "Earthman"

In The Desert Storm, Hua Chung portrayed a series of Chinese and Japanese characters. When she is shaping her character, she can transcend national prejudice, face human nature, and show the beauty and ugliness of human nature. Japanese Kimura planed to develop African diamond minerals in the name of transforming the Sahara's ecological environment. Eventually, his company went bankrupt, his reputation was corrupted and he went to be a monk. His partner died of AIDS. One of his helper was infected with AIDS, another one was shot in Africa. These people represented by Kimura did not hesitate to break the environment and dally with people for the sake of economic interests and material desires, and eventually they were deeply harmed. On the contrary, there are another group of Japanese who volunteer for hard work in order to protect the environment. For instance, Professor Endo, in order to help China prevent desertification, he still worked in the Kubuqi desert in his 70s. Kanno and Miyoko can give up everything for the environmental protection. They can disregard the danger of life to examine the feasibility of implementing water diversion schemes in the Sahara Desert, and can contribute to the education of African children and China's prevention of desertification.

\subsection{Exploring Cultural Motives: Adhering to the Mission of Literature and Creating a Third Space for Mixed Culture}

Hua Chun was educated in China since childhood. After graduating from university, she went to Japan to study at her own expense. After graduation, she worked successively with Japanese environmental protection agencies, law firm offices, and then founded her company. Hua Chun are unconventional on the subject selection, she is free from the constraints of personal emotions, and present a majestic and objective rationality, which is closely related to her cross-border living experience and cross-cultural life experience. Hua Chun's father once studied abroad in the Soviet Union, therefore, she has had a chance to read many Russian literary books when she was young. She prefers Russian literature that has grand scene and great themes, and shows the author's criticism of society and the value of life. The writing style of Russian literature has a great influence on the creation of Hua Chun.

In addition, work experience was also an important factor influencing the formation of Hua Chun's creative ideas. During worked in environmental protection agencies, she had chance to know many environmental protection materials and Japanese non-governmental environmental protection organizations, contact with people of all classes in Japan. She was deeply impressed by Japan's strong volunteer service spirit and used them as the source of her writing. The work experience in environmental agencies has broadened her horizons and changed her perspective. She thought that people should not only live in their own small world and indulge in their own little emotions, but need to open their eyes and mind, pay attention to the human community. This kind of value recognition is also reflected in her literary creation concept. She believed that literature should not be a simple catharsis of personal feelings, it needs to have "righteousness", and writers should have responsibility. She said at an academic symposium, "As for the theme of the Cultural Revolution, I have already considered it very mature... I can fully grasp the content, but compared with the fate of individuals and families, the fate of the Earth and all humanity is even more important. I find that people are very unconscious about the expansion of desire.... I think repeatedly, in any case, literature still needs to inspire people to reflect and give people upward power." (Hua, 2016)

Hua Chun not only thinks about the mission of literature, but also reflects this in literary creation. She seriously thought of the relationship between the individual and the country, and the relationship between China and Japan by her works.

Hua Chun Can contact many Japanese people from all walks of life while working in the environmental protection agencies and lawmakers. With the understanding of the Japanese, she learns about the complexity of the Japanese nation and the diversity of Japanese culture. At any time, neither single people nor government can represent the general public, at least not all of the public's thoughts. The historical resentment between China and Japan cannot be forgotten, but the past has passed, instead of immersing in extreme national sentiments, it is better to step out of the emotional enthusiasm, open eyes and mind, and keep your feet on the ground to make yourself, your country, and the world to be better. Hua Chun expressed her reflection on the relationship between the national development and historical past in "Miss Jasmine Red Handkerchief". Many Chinese people came 
to study in Japan in order to promote the development of economic in China and enable their children to live better. For every Chinese in a foreign country that has had a history of invading China, the motherland's strength, social stability and affluence are all the urgent desires of the overseas Chinese.

Whether it is in writing grand scenes on environmental topics or writing stories about Chinese people working in Japan, or writing essays of Japanese civilization and customs, Hua Chun is observing humanity with an objective and rational vision, with an "Earthman" perspective, which shows a mixed cultural space to readers. Despite this, from the works, readers can still feel that the biggest influence on her is Chinese culture. Lin Tingting, a North American Chinese writer, said that "One can have no political motherland, but he must have cultural motherland." Hua Chun is a Japanese on her identity card, she expresses her deep appreciation for Japanese culture and modern civilization, at the same time, and she still shows her nostalgia for her Chinese culture.

In The Desert Storm, Zhao Ni learned of the harsh living conditions of the Yellow River valley after a trip to northwest China, and saw the success of her first lover Pang Bin in tackling desertification. She deeply touched by the spirit of Professor Endo and Pang Bin. Finally, she gave up her marriage to Lu Bosheng who can give her luxurious life. She chose to return to the Kubuqi Desert, fight side by side with Pang Bin to control desertified land and protect the environment. When Zhao Ni refused Lu Bosheng, she said: "I went to the northwest and stood in a barren and disaster-prone land, found that all my personal suffering and the ups and downs are nothing, ......after all, think rationally, in addition to emotional and sexual harmony, what is it that can dominate one's life and love?" (Hua, 1998, pp. 296-297). It is the words of Zhao Ni, also the writer's inner monologue. What dominates her is not the pursuit and enjoyment of material things, but the sustenance of the soul and spirit, the realization of individual values and the constant emotion of reciprocating the motherland. Zhao Ni chooses Pang Bin instead of Lu Bosheng, this choice means that she want to choose a spiritual component more than love. She hopes to work side by side with a person who has a common culture and common ideal with him.

In many articles in the collection of The Temptation of Silk, it reflects the cultural exchanges and integration between China and Japan, and the influence of Chinese traditional culture on Japanese civilization. For example, in the prose "Leoh Ming Pei brings Oriental charm - Visiting Japan's Miho Museum", the author gasped with admiration at Pei's design that was inspired by Tao Yuanming's prose "The Peach Blossom Spring Story". Leoh Ming Pei is very familiar with Chinese traditional culture. He integrates architecture and the nature topography perfectly, so that China's traditional aesthetics can perfectly be practiced in Japan. For another example, in one article, the author wrote about the origin of the Hanshan Temple in Japan. When the Japanese artist studied in China, he visited the Hanshan Temple in Suzhou. After the consent of the Hanshan Temple abbot, he returned to Japan and built it under the artistic conception in the poem "Mooring by Maple Bridge at Night". In order to fully show the artistic conception of "Bells break the ship-borne roamer's dream and midnight still" in the poems, Hanshan Temple built a bell similar to the bell that in Suzhou. In the other works in the essay collection, the readers can also noticed the influence of Chinese culture on Japanese courtyard gardens, silkworm breeding, and silk manufacturing.

\section{Conclusion}

As a Chinese Japanese who travels between Japan and China, Hua Chun's cross-border life experience and cross-cultural perspective infiltrate all aspects of her work. In her works, she not only praises the excellent culture and advanced civilization of China and Japan, but also criticizes the goodness and evil of human nature. In Hua Chun's opinion, whether it is Chinese or Japanese, all of them are people of the earth. On the one hand, she identifies but does not stick to Chinese culture. On the other hand, she integrates but keeps a rational distance to Japanese culture. The diaspora experience and the third cultural space with hybridity by cross-culture experiences are the connotations and characteristics of the uniqueness of Hua Chun's works.

In terms of subject selection, Hua Chun can jump out of the convention of "nostalgia, homelessness" written by overseas Chinese writers. She chooses environmental protection topics, keeps away from ethnic historical sadness, abandons the ambiguity of national personal emotions, and faces human nature. Her creation has a unique personality in the history of Japanese Chinese literature and even the history of overseas Chinese literature.

\section{References}

Forster, E. M. (1927/1973). Aspects of the Novel (W. B. Li Trans.). Taipei: Zhi Wen Press.

Genette, G. (1980/1990) Narrative Discourse, New Narrative Discourse (W. R. Wang Trans.). Beijing: China Social Sciences Press.

Hua, C. (1998). Desert Storm. Beijing: Writers Publishing House. 
Hua, C. (2008). Miss Jasmine's red handkerchief. Today. Retrieved from http://www.jintian.net/today/html/63/n-2163.html

Hua, C. (2016). A speech at the conference on New Century, New Development, New Trends: Seminar on Japanese Chinese Literature, held at Jinan University in June 14, 2016.

Lu, S. Q. (2010, June). Japanese maple leaves are distinctive red: A brief talk on prose creation by Hua Chun, a Chinese writer in Japan. Forum for Chinese Literature of the World, (2), 46-49.

Zhang, Y. (2013, December). On the ecological complex of overseas Chinese Hua Chun's works. Overseas Chinese Journal of Bagui, (4), 52-55.

Zhang, Z. E. (2006, February). Facing the world and analyzing human nature: A review of overseas Chinese writer Hua Chun and her works. Culture Monthly, (2), 116-117.

\section{Copyrights}

Copyright for this article is retained by the author(s), with first publication rights granted to the journal.

This is an open-access article distributed under the terms and conditions of the Creative Commons Attribution license (http://creativecommons.org/licenses/by/4.0/). 